\title{
Pedro Díaz de Valdés (1740-1807) y el estudio de las ciencias naturales
}

\author{
JoRGE ORDAZ \\ Universidad de Oviedo
}

Resumen:

Se repasan las ideas y propuestas de Pedro Díaz de Valdés (1740-1807) relativas a la enseñanza y cultivo de las ciencias naturales en general y de las geológicas en particular. El asturiano Díaz de Valdés, obispo de Barcelona y académico de Ciencias, fue uno de los clérigos ilustrados más destacados de su tiempo. En diversos artículos y libros, como Tratados sobre la Física del Clero y El Padre de su pueblo, mostró su afición a la historia natural, aportando significativas observaciones en campos como la paleontología, la botánica y la mineralogía. Se interesó de modo preferente por la enseñanza de las ciencias naturales en los seminarios, con el objeto de formar curas párrocos versados en disciplinas útiles que pudieran trasladar sus observaciones a las Academias y sociedades patrióticas, y de esta forma contribuir a la mejora del país y de sus gentes. Díaz de Valdés propugnó asimismo la redacción de historias naturales provinciales y locales, el coleccionismo de productos naturales con fines instructivos y la elaboración de mapas mineralógicos y botánicos.

Palabras clave:

Ciencia. Historia natural. Enseñanza.

CES.XVIII, núm. 15 (2005), págs. 159-173. 
La promoción de la actividad científica y, en especial, de su divulgación y enseñanza, fue uno de los principales empeños que trataron de llevar a cabo, a lo largo del siglo XVIII, las minorías ilustradas españolas. Dicha promoción alcanzó su momento culminante durante el reinado de Carlos III, si bien algunas de sus realizaciones no se materializaron o adquirieron su máximo relieve hasta finales del siglo, durante el reinado de Carlos IV, cuando la crisis de la Ilustración era ya una realidad. En esta tarea de renovación y puesta al día en el campo científico participaron algunos notables representantes eclesiásticos. En Asturias, concretamente, destacan obispos reformadores y párrocos ilustrados que «se inscriben en las sociedades económicas, dan informes a Ensenada o al geógrafo Tomás López, y colaboran en la confección del Diccionario Histórico-Geográfico de Asturias de Francisco Martínez Marina» ${ }^{1}$. Es en este contexto regional e ideológico, que surge la figura de uno de estos clérigos ilustrados cuyo interés se centrará fundamentalmente en la enseñanza y cultivo de las ciencias naturales.

\section{Don Pedro Díaz de Valdés}

Pedro Díaz de Valdés y García-Argüelles nació en Gijón en $1740^{2}$, transcurriendo en Asturias los primeros años de su vida. Tras estudiar la carrera eclesiástica en el Colegio de San Pedro de Oviedo, conocido popularmente por el «de los verdes» debido al color del hábito de los colegiales, continuó los estudios en el Colegio de los Jesuitas; pasando luego a cursar Leyes y Cánones en la Universidad ovetense ${ }^{3}$. De los años posteriores a la conclusión de sus estu-

1 Silverio Cerra SuÁrez, «Iglesia asturiana e Ilustración en el siglo XVIII», Asturias y la Ilustración (Ed. José Miguel Caso González), Oviedo, Servicio de Publicaciones del Principado de Asturias, 1996, pág. 56.

2 El 8 de septiembre, según Constantino SuÁREz, Escritores y artistas asturianos, tomo III, Madrid, Imprenta Sáez, 1936, págs. 82-83. Otra fuente (http://www.catholic-hierarchy.org/bishop/bdiazva.html) señala el 10 de septiembre.

3 Datos biográficos sobre Pedro Díaz de Valdés se encuentran, entre otras fuentes, en: Manuel ÁLVAREZValdés y Valdés, La hidalguía. Caballeros asturianos de la Orden de Carlos III, Oviedo, KRK Ediciones, 1992, págs. 151 y ss. y 257; Manuel Álvarez-ValdÉs y ValdÉs, Jovellanos: enigmas y certezas, Gijón, Fundación Alvargonzález, 2002, págs. 237-261; Joan BADA, «Don Pedro Díaz de Valdés, obispo de Barcelona (17981807). Apuntes bibliográficos», Anthologica Annua, 19 (1972), págs. 651-674; Lluís Roura I Aulinas, «Pedro Díaz de Valdés: propuestas de un eclesiástico relativas a la guerra y la Revolución, en Cataluña (1793)», Trienio, 26 (1995), págs. 211-224; Enciclopedia Universal Ilustrada Europea-Americana, tomo XVIII (Primera Parte), Barcelona, Hijos de J. Espasa, Editores, Barcelona, pág. 896; Gran Enciclopedia Asturiana, tomo VI, Gijón, 1970, pág. 18; Real Academia de Ciencias y Artes, «Excmo. e Ilmo. Sr. D. Pedro Díaz de Valdés», Año Académico de 1905 a 1906. Nómina del Personal Académico, Barcelona, A. López Robert, Impresor, s.a., págs. 106-108. 
dios, se sabe que se graduó en derecho canónico en la Universidad de Burgo de Osma y posteriormente se trasladó a Madrid, donde trabó amistad con el también asturiano don Pedro Rodríguez de Campomanes, fiscal del tribunal supremo de Castilla; una amistad que se mantendría hasta el fin de sus días.

Con veinticinco años es Díaz de Valdés rector prebendado de la parroquia leridana de Agramunt. Desconocemos las razones que le trajeron a esta localidad de la diócesis de La Seu d'Urgell, lo que sí parece claro es que este destino como «cura de almas» en Agramunt fue crucial para su trayectoria de aficionado a la historia natural y para su decisión de permanecer en tierras catalanas. Provisor del obispado, fue premiado con una canonjía en el Cabildo catedralicio y con la dignidad de arcediano de la Cerdaña. En esta época consta que Díaz de Valdés fue corresponsal y suministró información sobre el actual Alt Urgell a la Real Junta de Comercio de Barcelona para la elaboración del Discurso sobre la agricultura, comercio e industria del Principado de Cataluña (1780) ${ }^{4}$. En 1779 pasa a la diócesis de Barcelona, donde sería nombrado canónigo, fiscal e inquisidor del Santo Oficio del Principado de Cataluña ${ }^{5}$.

En 1788 solicita plaza de académico en la Real Academia de Ciencias Naturales y Artes de Barcelona. Josep Comes, a la sazón censor de la Academia, leyó el preceptivo informe en la sesión de la Junta de 13 de febrero de $1788^{6}$. En él, además de inclinarse por la admisión que se solicita, Comes proporciona algunos datos biográficos y cargos desempeñados por Díaz de Valdés, y valora favorablemente sus méritos diciendo, entre otras cosas:

Prescindiendo de que la inclinación al examen de los tres reinos de la Naturaleza, y principalmente a herborizar, cuando se mantuvo el Sr. Valdés en Ayremunt (sic) y después en Urgel, conducido por los principios de Linneo y otros autores clásicos, le hizo adquirir unos conocimientos nada comunes en las ciencias naturales; demuestra también lo que ha medrado en estos estudios el «Discurso sobre la necesidad de una Física provechosa con que el Clero y particularmente los curas párrocos harían un gran bien a la nación»?

4 Véase Ernest Lluch, Las Españas vencidas del siglo XVIII. Claroscuros de la Ilustración, Barcelona, Crítica, 1999, pág. 221. Hay edición del Discurso del propio E. Lluch., Barcelona, 1996.

5 Antonio Astorgano Abajo, en «El fiscal inquisidor don Nicolás Rodríguez Laso en Barcelona (17831794)», Bol. R. Acad. de Buenas Letras de Barcelona, XLVII (1999-2000), Anys acadèmics CCLXXI-CCLXXII, pág. 239, refiere que por estos años de 1780, Díaz de Valdés vivía amancebado con una supuesta «hermana»o «prima», lo que al parecer no fue óbice para que alcanzase los mencionados puestos de responsabilidad.

6 José Iglesies Fort, La Real Academia de Ciencias Naturales y Artes en el siglo XVIII, Memorias de la Real Academia de Ciencias y Artes de Barcelona, Tercera Época, núm. 707, vol. XXXVI, núm. 1, Barcelona, 1964, 544 págs.

7 R. A. de C. y A., Año académico, pág. 106. 
Díaz de Valdés fue admitido como socio numerario, y destinado a la Dirección de Historia Natural, en 27 de febrero del mismo año de 1788. Tomó formalmente posesión de su plaza el día 12 de marzo, en que leyó su oración gratulatoria. En los años 1788 y 1789 fue elegido revisor de la Dirección de Historia Natural, y en 1790 y 1791 ocupó el cargo de censor de la Academia. Su principal contribución en este tiempo fue la disertación, leída en las sesiones de 23 de febrero y 16 de marzo de 1791, titulada «Discurso previo sobre la Historia Natural con respeto (sic) a Cataluña $»^{8}$, y en la que, entre otras cosas, se señala la utilidad de que se escribiese una historia natural del Principado, a semejanza de la que ya había escrito de Asturias el médico Gaspar Casal’:

Dos Principados tiene nuestro Monarca en España: uno hacia el Océano, que es mi patria natural; y otro hacia el Mediterráneo, que es mi patria adoptiva. El primero debió al señor Gaspar Casals (sic) una Historia natural que merece mejorarse con las actuales luces: el segundo, no sé que tenga un libro destinado por entero a tan noble asunto ${ }^{10}$.

No obstante, viéndose Díaz de Valdés imposibilitado de atender sus compromisos con la Academia, por mor de sus múltiples ocupaciones eclesiásticas, acabó renunciando a su plaza de académico al cabo de poco tiempo. Así, en la sesión de la Junta de 17 de octubre de 1792, el marqués de Lupià, presidente de la Academia, dio cuenta de un oficio de fecha 16 de julio del mismo año en que:

el socio don Pedro Díaz de Valdés me había devuelto el título de Académico, diciendo que para atender sin distracción a ciertos negocios propios le era preciso privarse de la asistencia en las Juntas rogándome que al mismo tiempo de hacerlo presente a la Academia la asegurase de su agradecimiento a los favores que le había dispensado y de su pronta voluntad a obsequiarle en cuanto gustase mandarle ${ }^{11}$.

8 Existe original manuscrito de este discurso en los archivos de la Real Academia de Ciencias y Artes de Barcelona. Consta de 57 parágrafos en 30 folios, y corresponde en su integridad a la versión impresa que aparece en Pedro Díaz de VaLdés: Tratados sobre la Física del clero, y otros puntos útiles y provechosos de las ciencias naturales, impresos en el Memorial literario de Madrid de 1787, 1789, 1790 y 1793. Reimprímense ahora, añadido un discurso sobre la Historia natural con respecto a Cataluña. Barcelona, Manuel Texero, 1806, 217 págs.

9 Se refiere a la obra póstuma de Gaspar Casal, Historia natural y médica del Principado de Asturias, Madrid, Oficina de Manuel Martín, 1762.

10 «Discurso sobre la Historia Natural con respecto a Cataluña», en Pedro Díaz de Valdés, Tratados sobre la Física del clero.., págs. 12-13. Seguramente Díaz de Valdés desconocía la existencia de la obra de su coetáneo Mateu Aymerich, S.J. (1715-1799) titulada Historia Geographica y Natural del Principado de Cataluña, escrita sobre la base de la compuesta a principios del siglo XVII por Pere Gil, S.J., y que, pese a haber recibido en Madrid licencia de impresión en 1766, acabó inédita.

11 Iglesies Fort, La Real Academia de Ciencias Naturales, pág. 584. 
En vista de lo cual se acordó que se le contestase, aceptando su dimisión en términos igualmente atentos.

La amistad de Díaz de Valdés con su paisano Gaspar Melchor de Jovellanos, con el que mantuvo correspondencia ${ }^{12}$, fue decisiva para que, siendo éste ministro de Gracia y Justicia, fuera nombrado en 1798 obispo de Barcelona ${ }^{13}$. Díaz de Valdés siempre le estuvo agradecido por este gesto y, cuando Jovellanos cayó en desgracia y fue encarcelado en Mallorca, el obispo de Barcelona fue prácticamente el único entre amigos e instituciones — aparte de lord Holland- que intercedió por el ilustre polígrafo, aunque con resultados negativos ${ }^{14}$. En opinión de Pérez Samper ${ }^{15}$, Díaz de Valdés era el modelo de prelado fiel a la monarquía y a la persona que entonces encarnaba la institución, Carlos IV. Esta incondicional devoción al rey y a la familia real le parecía excesiva a su contemporáneo barcelonés el barón de Maldá, el cual tildaba al obispo de «massa realeng» ${ }^{16}$. Carlos IV, por su parte, le agradeció su lealtad otorgándole el título de consejero de Su Majestad y la Gran Cruz de la Orden de Carlos III. Díaz de Valdés murió en la ciudad condal el 15 de noviembre de 1807.

Además de diversos textos religiosos, sermones, edictos y otros documentos episcopales ${ }^{17}$, el grueso de los escritos de Díaz de Valdés lo forman varios textos relacionados con las ciencias naturales, la mayoría de los cuales vieron la luz por vez primera en la revista Memorial Literario Instructivo y Curioso de la Corte de Madrid ${ }^{18}$. En diciembre de 1786, bajo el epígrafe «Filosofía», apareció un escrito fechado en 15 de noviembre y remitido por «un suscriptor residente en la ciudad de Barcelona», titulado «Progresos útiles a la nación», que posteriormente reconocería Díaz de Valdés como suyo ${ }^{19}$. Con el pseudónimo de «Pedro

12 Véase Gaspar Melchor de Jovellanos, Obras completas, «Correspondencia», tomos II, III y IV (edición de José Miguel Caso González), Instituto Feijoo de Estudios del Siglo XVIII y Ayuntamiento de Gijón, 1984, 1986 y 1988.

13 Cfr. Álvarez-Valdés (2002), Jovellanos: enigmas y certezas, págs. 237-238. Díaz de Valdés fue nombrado obispo el 14 de septiembre de 1798 y ordenado el 24 de febrero de 1799.

14 Cfr. Álvarez-Valdés (2002), Jovellanos: enigmas y certezas, pág. 243.

15 María de los Ángeles Pérez Samper, Barcelona, Corte. La visita de 1802. Publicaciones de la Cátedra de Historia General de España, Barcelona, 1972, págs. 82 y ss.

16 Pérez Samper, Barcelona, pág. 86.

17 Véase relación de impresos en Antonio Palau y Dulcet, Manual del librero hispanoamericano, tomo cuarto, Barcelona, Librería Palau, 1951, pág. 435; y Francisco Aguilar Piñal, Bibliografía de autores españoles del siglo XVIII, tomo II (D-F), Instituto Miguel de Cervantes, Madrid, CSIC, 1984, págs. 49-51.

18 Véase Inmaculada URZAinQui, «Aportación asturiana a la prensa ilustrada», Asturias y la Ilustración, págs. 205-256. También Jesús Sánchez MiñanA, «La colaboración del Dr. Salvá y Campillo con el Memorial Literario de Madrid (1786-1790): una ventana sobre el paisaje científico y sus figuras en la Cataluña de finales del XVIII», Quaderns d'Història de l'Enginyeria, vol. IV (2000), págs. 184-230.

19 En el «Discurso sobre la necesidad de una Física provechosa con que el Clero, y particularmente los Curas Párrocos, harían un gran bien a la Nación» (ML, diciembre 1786; septiembre, octubre y noviembre, 1787). 
Zadidalvés» ${ }^{20}$ aparecerán también en el Memorial Literario, entre 1787 y 1793 , una serie de artículos que en 1806 serían reimpresos en forma de libro con el título de Tratados sobre la Física del Clero y otros puntos útiles y provechosos de las Ciencias Naturales ${ }^{21}$. Los artículos reunidos en dicho libro son: «Discurso sobre la necesidad de una Física provechosa, con que el Clero, y particularmente los Curas Párrocos, harían un gran bien a la Nación ${ }^{22}$, mencionado en el informe sobre Díaz de Valdés del académico censor Comes; «Carta sobre los Hongos, y remedio de los venenosos; y sobre dos especies de aceites que pueden suplir el de aceitunas para alumbrar ${ }^{23}$; «Sobre algunas raras petrificaciones, y sobre la importancia de la Historia Natural ${ }^{24} \mathrm{y}$ «Carta sobre si la Escabiosa es un específico para curar la mordedura de la víbora, y sobre algunos remedios contra su veneno» ${ }^{25}$. El libro se completa con el mencionado «Discurso sobre la Historia Natural con respecto a Cataluña», compuesto en 1791.

\section{Díaz de Valdés y los inicios de la Paleontología española}

Si bien la preferencia de Pedro Díaz de Valdés, dentro de las ciencias naturales, se decantó por la botánica ${ }^{26}$, su aportación al campo de la incipiente paleontología española no es desdeñable. Su importancia en este campo deriva sobre todo de su publicación «Sobre algunas raras petrificaciones...», reconocida ya en el siglo XIX por diversos autores como un trabajo pionero ${ }^{27}$, si bien el nombre de su autor no siempre aparezca en estudios posteriores sobre historia de la geología en España ${ }^{28}$. Maffei y Rúa Figueroa, al comentar el citado artículo,

20 Anagrama parcial de sus apellidos. C. SuÁREz, Escritores y artistas, pág. 82, escribe «Pedro Zadivaldés». El mismo error se repite, también, en otros autores.

21 Véase nota 8.

22 Véase nota 18.

$23 \quad M L$, junio 1789.

$24 \quad M L$, mayo y junio 1790 .

$25 \quad M L$, diciembre 1793

26 Miguel Colmeiro, en el catálogo de obras botánicas incluido en La botánica y los botánicos de la península hispano-lusitana, Imprenta de Rivadeneyra, Madrid, 1858, menciona la carta sobre los hongos de Pedro Zadidalvés, pero no el trabajo sobre la escabiosa.

27 Eugenio Maffei y Ramón Rúa Figueroa, Apuntes para una Biblioteca Española de libros, folletos y artículos, impresos y manuscritos, relativos al conocimiento y explotación de las riquezas minerales y a las ciencias auxiliares, tomo II, Madrid, Imprenta de J.M. Lapuente, 1872; Manuel FernándEZ DE CASTRo, Notas para un estudio bibliográfico sobre los orígenes y estado actual del Mapa Geológico, Madrid, Bol. de la Comisión del Mapa Geológico de España, tomo I, 1874.

28 No es citado, por ejemplo, en Norbert Font I SAGuÉ, Història de les Ciències Naturals a Catalunya del sigle IX al sigle XVIII, Barcelona, Estampa de la «Hormiga de Oro», 1908; y en Juan Manuel LóPEZ DE AzconA y José Meseguer Pardo, Contribución a la historia de la geología y minería españolas, Madrid, Inst. Geol. y Min. de España, 1964. 
dicen del mismo que «es un escrito de bastante doctrina y erudición científica, manifestando su autor un excelente criterio que le separa de la mayor parte de los naturalistas de su tiempo» ${ }^{29}$.

Por su parte, Francisco Pelayo valora la contribución de Díaz de Valdés al conocimiento de los fósiles ${ }^{30}$, resaltando su apuesta por el origen orgánico de los mismos. En esta línea, Díaz de Valdés cita diversos fósiles marinos procedentes de los terrenos calcáreos de las localidades leridanas de Agramunt y Salàs, en el corregimiento de Talarn. Tras exhortar sobre la necesidad de que los grabados que aparecen en orictografías, catálogos de fósiles y tratados de petrificaciones debieran ejecutarse con el máximo primor y fidelidad a fin de que puedan ser fácilmente identificadas las especies, Díaz de Valdés menciona concretamente en Agramunt la presencia de estrellas de mar o asterias $^{31}$, trochitas, así como entroques $^{32}$ y "palmas marinas»; y en Salàs de encrinitas ${ }^{33} \mathrm{o}$ «lirios de piedra», corales Alcyonium, «hongos marinos» e «higos petrificados». También identifica pequeñas conchas en la lumaquela o «piedra marmórea» de las columnas del claustro de la iglesia de Santa Ana de Barcelona ${ }^{34}$. En ambos casos reconoce como bastante común «la opinión que afirma que estos cuerpos marinos fósiles fueron en otro tiempo habitantes de los mares que cubrían los países donde se descubren», coincidiendo en esto con hipótesis expuestas por autores precedentes, como el padre Feijoo ${ }^{35}$ — con el que disiente en cuanto al proceso de fosilización-, y alejándose por tanto de otros naturalistas más estrictamente partidarios del diluvio universal, como el padre Torrubia ${ }^{36}$.

29 Maffei y Rúa FigueroA, Apuntes para una Biblioteca, pág. 268.

30 Francisco Pelayo, Del Diluvio al Megaterio. Los orígenes de la Paleontología en España, Madrid, Cuadernos Galileo de Historia de la Ciencia, 16, CSIC, 1996.

31 En el texto aparece escrito, por error, asserias.

32 Trochitas o trochites: artejos (segmentos articulados) del tallo de un crinoideo fósil. También se usa troquita. Entroques: conchas o estrellas de mar petrificadas, en que se encuentran las vértebras o espinas de algún pez (Enciclopedia Espasa). Puede tratarse asimismo de entrocas: fragmentos de tallos de crinoideos, formados por varias troquitas.

33 Encrinita: crinoideo fósil parecido al género Encrinus. Por extensión, roca (normalmente caliza) que contiene abundantes restos de crinoideos.

34 En realidad no se trata de una lumaquela (roca calcárea formada mayoritariamente por restos de moluscos), sino de una caliza con foraminíferos, posiblemente eocénica. En otro pasaje (nota de la pág. 192) cita también la presencia de dicha piedra en el patio alto de la Audiencia de Barcelona. Otros fósiles mencionados por Díaz de Valdés en este artículo son las terebrátulas y los «cuernos de Ammon» (amonitas) de Cuenca (pág. 178).

35 Las ideas de Feijoo sobre el origen y naturaleza de los fósiles se hallan expuestas, principalmente, en «Solución del gran problema histórico sobre la población de América, y revoluciones del orbe terrestre» (Teatro Crítico Universal, tomo V, disc. XV, 1733) y «Peregrinaciones de la naturaleza» (Teatro Crítico Universal, tomo VII, disc. II, 1736).

36 Cfr. Franciso Pelayo, «El Aparato para la Historia Natural Española de José Torrubia (1698-1761): diluvismo, gigantes y la naturaleza de los fósiles en el pensamiento español del siglo XvIII», Aparato para la 
Por otro lado, en dicho artículo Díaz de Valdés abordaba, tal vez por primera vez en España, la posibilidad de que la voz hebrea del Génesis que hacía referencia a los «días» de la creación pudiera referirse a épocas o intervalos extensos de tiempo, aunque sin llegar a los extremos de Buffon, quien sostenía la necesidad de aumentar en varias decenas de miles de años los seis mil años de antigüedad atribuidos a la Tierra según la cronología bíblica tradicional. ${ }^{37}$. Así pues, puede decirse que las ideas paleontológicas de Díaz de Valdés resultan bastante avanzadas tanto en la interpretación sobre el origen y naturaleza de los fósiles como en la concepción de una edad más remota para la Tierra y las especies que en tiempos prehistóricos la poblaron.

\section{Utilidad de las ciencias naturales}

En 1806 Díaz de Valdés publica El Padre de su Pueblo, o medios para hacer temporalmente felices a los pueblos, con el auxilio de los señores curas párrocos ${ }^{38}$, memoria que había sido premiada por la Real Sociedad Vascongada, e impresa de su orden en Vitoria en 1793.

En dicha publicación, así como en otros artículos, expone Díaz de Valdés sus ideas acerca del cultivo y enseñanza de las ciencias naturales, su utilidad y provecho, así como la conveniencia de que los eclesiásticos en general, y los párrocos en particular, tengan cabal conocimiento de las mismas. Ya en el primerizo artículo «Progresos útiles a la nación» ${ }^{39}$ encontramos las líneas clave de su pensamiento, manifestando a este respecto su apuesta, siguiendo a Bacon, por el método empírico, y el deseo de que los eclesiásticos, que poseen «ingenio, tiempo, aplicación y proporción para observar el gran libro de la Naturaleza», se aficionen a estos estudios de las ciencias naturales, y así puedan trasladar sus observaciones «a las Academias o Sociedades patrióticas, donde como a centro común, fuesen a parar todos los nuevos descubrimientos y de donde se comunicasen a todo el Reino, a beneficio común»; precisando por otro lado que «los

Historia Natural Española (Madrid, 1754), de J. Torrubia, edición facsímil, Madrid, Instituto de Geología Económica, CSIC, 1994, págs. 3-45. Díaz de Valdés no menciona explícitamente al franciscano padre Torrubia en su artículo, aunque era conocedor del Aparato, como él mismo atestigua en su «Discurso sobre la necesidad de una Física provechosa».

37 Cfr. Pelayo, Del Diluvio al Megaterio, pág. 255.

38 Pedro Zadidalvés, El padre de su pueblo, o medios para hacer temporalmente felices a los pueblos, con el auxilio de los señores curas párrocos. Memoria premiada por la Real Sociedad Bascongada e impresa en Victoria en 1793.Reimpresa ahora, con un discurso previo y algunas notas. Barcelona, Manuel Texero, 1806. 172 págs.

$39 M L$, diciembre, 1786. 
Señores Curas habrían de ser los observadores natos de las producciones de las Parroquias» siendo «el primer cuidado y que más nos importa [...] el de conocer las riquezas nacionales, comenzando cada cual por las que tiene cerca de sí». Así pues, el establecimiento de un vínculo entre los clérigos y las academias a través del estudio de la naturaleza resulta crucial en el sentir de Díaz de Valdés.

En su artículo «Sobre algunas raras petrificaciones...» tampoco pierde la ocasión para animar a la búsqueda y estudio de los fósiles, diciendo, por ejemplo, que «esta contemplación curiosa de tantas preciosidades, como algún día atendíamos en nuestros paseos, es un medio honesto para entretener dichosamente alos Eclesiásticos que viven en el retiro de las soledades» ${ }^{40}$.

En su discurso sobre la historia natural de Cataluña, Díaz de Valdés aprovecha para recalcar la utilidad de las ciencias naturales frente a las «sistemáticas», abstractas y especulativas; ya que «las ciencias, fundadas en la naturaleza, crecen y aumentan [...]: las que estriban en meras opiniones, producen algunas variedades, pero ningunos aumentos» ${ }^{41}$. En otro pasaje precisa:

Conocer, nombrar y describir un vegetable, mineral o un insecto, es la primera operación de un naturalista; saber sus usos principales, es la segunda, y la que más importa [...]. La Historia natural que no sirve de base a la ciencia económica que no atiende a la perfección de la agricultura, que no presta socorros a la medicina, ni enseña auxilios a las artes, es un conocimiento inútil, que deja desairado al naturalista, y le roba las horas necesarias para las meditaciones interesantes ${ }^{42}$.

Y por si no quedase suficientemente claro, más adelante remacha:

Repito otra vez: la primera operación de un naturalista es conocer el material; la segunda, saberlo usar; y la tercera, averiguar todos los modos de aprovecharle con menos coste, y más utilidad general ${ }^{43}$.

\section{Las enseñanzas científicas en los seminarios}

Donde Díaz de Valdés habla con mayor detenimiento acerca de la necesidad y utilidad de los citados conocimientos científicos, así como de su práctica y enseñanza, es en el artículo «Sobre la necesidad de una Física provechosa...»

\footnotetext{
$40 \quad$ Tratados sobre la Física del clero, pág. 193.

41 Idem, pág. 4.

42 Idem, págs. 30-32.

43 Idem, pág. 53.
} 
y en El Padre de su pueblo. En el citado artículo el autor asturiano insiste en alejarse de las especulaciones científicas que no conducen «a la sólida instrucción de los hombres para ser virtuosos, en sí mismos, y útiles a la sociedad humana...» ${ }^{44}$. Estos estudios útiles deberían ser abanderados por los eclesiásticos, en especial por los curas párrocos de los pequeños pueblos, a fin de que puedan comunicarlos a sus feligreses y conseguir así el mejor aprovechamiento de los recursos y en general de sus vidas:

Si los que escriben desde sus cómodas habitaciones, y en los pueblos grandes, donde nada falta, vieran el estado de los infinitos Lugarcitos de la Nación (que son los más en ella), su miseria, su abandono, y una casi total carencia de lo necesario; a buena fe, que dejarían por un instante el lujo y la pompa de los estudios brillantes e infructuosos para escribir lo que es de uso común, y de una general necesidad. ¡Pueblos miserables, que con vuestro sudor ayudáis a mantener las carrozas de las Capitales soberbias, y que dais al Estado los miembros más robustos para su defensa! Yo os compadezco ${ }^{45}$.

Este afán científico de buscar en el estudio y explotación de los recursos naturales el mejoramiento de la vida de los hombres y el progreso de los pueblos es una idea que Díaz de Valdés comparte con otros autores y, en especial, con su paisano y amigo Jovellanos ${ }^{46}$.

Una vez asumido que la enseñanza de la «verdadera Física» tiene por objeto principal la «mejora del país» y la «felicidad de sus gentes», la manera de poner en marcha este objetivo es básicamente a través de la impartición en las aulas de la Química, la Mineralogía y la Botánica, las tres ramas científicas que Díaz de Valdés considera más útiles para sus propósitos ilustrados. En el caso de los seminarios eclesiásticos, dichas enseñanzas deberían costearse con cargo a la propia Iglesia:

La dotación del clero de cada provincia u obispado tiene destino, según la mente de los que la asignaron, y lo que han arreglado los cánones, a mantener las Iglesias y sus Ministros, dándoles cuanto es menester, para que se proporcionen al desempeño de sus funciones. La instrucción del clero exige de aquella todo lo necesario para conseguirla. Al seminario de la capital deben contribuir todas las

\footnotetext{
44 «Discurso sobre la necesidad de una Física provechosa», en Tratados sobre la Física del Clero, pág. 94. La cursiva es de Díaz de Valdés.

45 Idem, págs. 106-107.

46 Véase, por ejemplo, el discurso «Sobre la necesidad de cultivar en el Principado el estudio de las ciencias naturales», que Jovellanos leyó en la Sociedad Económica de Amigos del País en 1782.
} 
iglesias de la diócesis; porque se trata y procura el bien de todas con la enseñanza que en él se diere ${ }^{47}$.

Por otro lado, en la segunda parte de El Padre de su pueblo, dedicada expresamente a «los medios con que los curas podrán ayudar a la felicidad, prosperidad y riqueza de los pueblos», vuelve Díaz de Valdés a proponer la instrucción en los seminarios de las antedichas materias científicas, sin por ello «trastornar los estudios recibidos en las Universidades». En el caso concreto del estudio de la Mineralogía debieran incluirse, según él, no solo los minerales sensu stricto, sino también las tierras, rocas, sales, suelos, etc. Es decir, todo lo que podríamos encuadrar dentro de materiales geológicos ${ }^{48}$.

El interés por este tipo de estudios arranca en España especialmente a partir de las observaciones de Guillermo Bowles ${ }^{49}$, y es en gran medida compartido por las elites ilustradas ${ }^{50}$. Dichas enseñanzas, sin embargo, no habrían de limitarse solo al aprendizaje de los conocimientos meramente teóricos. Por el contrario, Díaz de Valdés insiste siempre en la vertiente práctica de dichas enseñanzas:

Para esto tendrá el Seminario un jardinito botánico, y un herbario seco, con una colección de minerales que sirvan diariamente a estas lecciones; de manera que el maestro, en cuanto lo permitan el jardín o herbario, y la colección, después de haber explicado la lección del día, les enseñe las plantas, o minerales, de que hubiesen hablado ${ }^{51}$.

Para la enseñanza específica de los minerales afirma Díaz de Valdés que:

sirve más frecuentar las minas, y oir a los que trabajan en ellas, que leer muchos libros, muchas veces falaces y superficiales. En efecto Boyle confesaba ingenua-

$47 \quad$ Idem, pág. 127.

48 Hay que recordar que los términos «geología» y derivados no eran de uso corriente todavía en España, aunque Jovellanos los emplea por estas mismas fechas en su Descripción del castillo de Bellver. Díaz de Valdés no los utiliza. De hecho, la primera inclusión de la palabra «geología» en el diccionario de la Real Academia es en la quinta edición (1817).

49 El irlandés William Bowles (c.1720-1780) fue llamado en 1752 por el gobierno español, a instancias de Antonio de Ulloa, para impulsar, entre otros estudios, los relativos a la minería. Su obra Introducción a la historia natural y a la geografía física de España (Madrid, 1775) alcanzó gran notoriedad, se hicieron otras dos ediciones (1782, revisada por José Nicolas de Azara, y 1789), fue traducida al italiano y al francés (1776 y 1783) y adaptada al inglés por John Talbot Dillon (1780).

50 En esta línea estarían, por ejemplo, dos paisanos suyos: Jovellanos proponiendo el estudio de los minerales en el Real Instituto Asturiano de Náutica y Mineralogía; o el conde de Toreno, con sus discursos sobre varios mármoles y minerales del Principado de Asturias (véase nota 56).

$51 \quad$ Idem, pág. 129. 
mente, que más había aprendido con los arquitectos y canteros, para conocer los géneros, diferencias, propiedades y naturaleza de las piedras, que con la lectura de Aristóteles, Plinio y sus comentadores. Es cierto que los antiguos naturalistas no caracterizaron bien las tierras y piedras; y por esto es muy difícil atinar con muchas de las que hablan en sus obras ${ }^{52}$.

\section{Otras propuestas}

También recomienda Díaz de Valdés la ejecución de cartas o mapas económicos, de carácter botánico, zoológico y mineralógico. En concreto, el mapa mineralógico «apuntaría los territorios calcáreos, los minerales \&c.», y a este respecto menciona los mapas confeccionados por Guetard y Solavie $(\text { sic })^{53}$. Una vez obtenidos estos mapas físico-económicos, y además el detalle de las producciones y artefactos del territorio que abracen, entonces se harán combinaciones interesantes, con presencia del censo español, o numeración de pueblos y sus clases, y se conocerá lo que entre éstas haya de perjudicial y de excesivo ${ }^{54}$.

Con estas sugerencias Díaz de Valdés se erige en uno de los primeros valedores de las ventajas que habrían de tener con el tiempo, para el desarrollo económico de las diferentes regiones españolas, los mapas geológicos, y cuya realización solo tendría lugar décadas después, en pleno siglo XIX, con la creación de la Comisión para formar la Carta geológica de Madrid y la general del Reino $^{55}$.

Otra de las ideas que Díaz de Valdés propugnó es la de la formación, con fines instructivos, de colecciones de productos naturales. Es posible que en esta faceta tuviese en cuenta los afanes coleccionistas de su paisano Joaquín José Queipo de Llano, conde de Toreno, que en su palacio de Cangas de Narcea guardaba una importante colección de minerales y mármoles ${ }^{56}$. En este sentido, Díaz de Valdés hace en el «Discurso sobre la necesidad de una Física provechosa con el Clero...» un elogio de la enseñanza de la historia natural a impartir a los futuros sacerdotes, señalando que la Física que se enseñe en los seminarios:

\footnotetext{
$52 \quad$ Idem, pág. 130.

53 Jean Étienne Guettard (1715-1786). Mineralogista francés, autor del Atlas et description mineralogiques de la France (París, 1780). Jean-Louis Giraud Soulavie (1752-1813). Naturalista e historiador francés, escribió Histoire naturelle de la France méridionale (París, 1780-1784), en siete volúmenes.

$54 \quad$ Idem, pág. 131.

55 Promulgada por Real Decreto de 12 de julio de 1849.

56 Emilio Marcos Vallaure, «El V conde de Toreno», introducción a: Conde de Toreno, Descripción de varios mármoles, minerales y otras diversas producciones del Principado de Asturias y sus inmediaciones (1785), Oviedo, Biblioteca Popular Asturiana, 1978, págs. 7-62.
} 
sería infinitamente más fructuosa, si cada seminario conciliar tuviese una coleccioncita de minerales, donde se enseñase a los ojos lo que se estudiase en los cuadernos; pues jamás se debería discurrir, ni tratar de producción alguna natural, sin tenerla presente, y enterarse bien de lo que es $^{57}$.

A este respecto, Nicolau y Valls ${ }^{58}$ relacionan esta sugerencia del obispo Díaz de Valdés con la fundación en 1818, en tiempos del obispo Pablo de Sitjar ${ }^{59}$ de una especie de gabinete de Historia Natural en el Seminario Conciliar de Barcelona. La creación del «Museo de cosas antiguas y preciosas de la Provincia», que había sido una iniciativa de Ignacio Torres Amat, la llevó a cabo su hermano Félix ${ }^{60}$, y quedó instalado al lado de la biblioteca del Seminario. El museo abarcaba un pequeño monetario, además de una colección de fósiles, minerales y plantas, que funcionaba a modo de laboratorio de ciencias naturales ${ }^{61}$.

Díaz de Valdés señala asimismo la utilidad de las historias naturales provinciales y locales, cuya elaboración, «para que sea provechosa, y para que figure bien entre los sabios», debería contar con la colaboración de académicos y facultativos especialistas en diferentes materias (Medicina, Botánica, Física, Mineralogía, Química, etc. ${ }^{62}$.

En cuanto a la redacción de los tratados de Física (incluyendo dentro de esta denominación a las ciencias «naturales», frente a las «abstractas»), Díaz de Valdés recomienda la lectura previa de autoridades, encabezadas por el canciller Bacon ${ }^{63}$, y señalando a Paulian ${ }^{64}$ como autoridad de referencia en cuanto al método a seguir. El primer tratado debería estar dedicado a la Física general

57 Tratados sobre la Física del clero, pág. 123.

58 Francesc Nicolau y Joan Valds, El Dr. Almera i la seva escola de geologia, Barcelona, Edicions Terra Nostra, S.A., 1987, págs. 15-16.

59 Pablo de Sitjar y Ruata (1747-1831) sucedió en 1808 a Díaz de Valdés como obispo de Barcelona.

60 Ignacio Torres Amat (1768-1811), sacerdote, fue bibliotecario de la Biblioteca Pública Episcopal. Su hermano Félix Torres Amat (1772-1847) era vicario general de la diócesis de Barcelona. Más tarde fue obispo de Astorga (1835).

${ }_{61}$ Este gabinete se puede considerar como el embrión del Museo de Geognosia y de Paleontología, fundado en 1874, en el mismo Seminario de Barcelona, por el geólogo y profesor de Historia Natural dicho centro, doctor Jaume Almera (Nicolau y Valls, El Dr. Almera, pág. 16).

${ }^{62}$ «Discurso sobre la historia natural con respecto a Cataluña», Tratados sobre la Física del clero, pág. 21.

63 Francis Bacon es, junto con Linneo, uno de los autores más citados por Díaz de Valdés en relación con las ciencias naturales. Entre los autores españoles más citados por Díaz de Valdés en sus artículos están: Jovellanos, Feijoo, Casal, conde de Toreno, Ulloa, Quer, Sarmiento y varios consocios académicos. Otras autoridades mencionadas: Plinio, Newton, Muratori, Boyle, Pluche, Ellis, Lister, Luid (i.e. Lhwyd), Bowles, Burtin, Pallas, Tournefort, Valmont de Bomare, Bergman, Proust, Réaumur, Ward, Spielmann...

64 Aimé Henri Paulian (1722-1801), físico francés, profesor de esta ciencia en Aix y Aviñón. Escribió, entre otras obras, Traité de Paix entre Descartes et Newton (1763) y La Physique mise à la portée de tout le monde (1791). 
y contener noticias claras, pero sucintas, de los principales sistemas; después vendría la Física particular, que incluiría la «Física terrestre, en que se ha de proceder con mayor extensión, por ser de una utilidad mayor» ${ }^{65}$, y en la que se tratarían asuntos útiles relativos a la Historia Natural, Química, etc. En la tercera parte de la Física terrestre se trataría de:

la naturaleza de los principales fósiles; de los fuegos subterráneos; de los terremotos que causan; y de la analogía de éstos con el trueno. La noticia de las piedras ordinarias y preciosas, la sal gemma, el nitro, el azufre \&c. conducirá mucho a los jóvenes; sacando de los mejores Químicos, entre otros Beaumé, lo mejor y de más utilidad. [...] Con esto se tendría una Física de uso común, muy conveniente a toda clase de ciudadanos, y que sería provechosa en cualquiera estado, a que se $\operatorname{aplicasen}^{66}$.

Es claro que muchas de las ideas de Díaz de Valdés referidas al estudio de las ciencias naturales representan una innovación en su momento y resultan muy novedosas, e incluso atrevidas, comparadas con las ideas francamente reticentes, cuando no contrarias, mantenidas por otros autores coetáneos, clérigos o no. Es de pensar, pues, que debido a la autoridad que representaba el obispo y académico Díaz de Valdés, sus recomendaciones a los curas párrocos (dedicación al estudio de las producciones naturales de sus parroquias, implicación en sociedades patrióticas y academias, formación de colecciones, etc.) tendrían que haber tenido en su momento mayor repercusión de la que en realidad tuvieron. Hay que reconocer, sin embargo, que las circunstancias políticas, sociales y económicas imperantes en España a finales del siglo XVIII y principios del XIX, con su repliegue claramente conservador, no fueron las más adecuadas para este tipo de actividades. En este sentido, no deja de ser paradójico que sea en este período de crisis precisamente cuando las instituciones científicas ilustradas y las obras de muchos de sus propulsores alcanzan mayor grado de madurez. Pero, como ya se ha señalado, el espíritu ilustrado concluye a finales del siglo con una clara involución reaccionaria. El resultado es la paralización, cuando no abierta oposición, de las acciones ilustradas, por lo que no es de extrañar que las ideas e iniciativas de Díaz de Valdés no llegasen a fructificar. No obstante, la incorporación de asignaturas como la Geología en los planes de estudio de los seminarios conciliares, a mediados del siglo XIX ${ }^{67}$, vendrían en

\footnotetext{
65 Idem, pág. 115.

66 Idem, págs. 121-123.

67 Véase, por ejemplo, el manual Elementos de Geología Sagrada, para uso de los Seminarios y Colegios, del abate Danielo (Tudela de Navarra, Imprenta y Librería Tudelana, 1854).
} 
parte a darle la razón, si bien la inclusión de este tipo de disciplinas tenía más que ver con la preparación de los futuros sacerdotes para poder combatir determinadas teorías desde la concordancia de la ciencia con el relato bíblico, que con el interés en cuanto a conocimientos útiles para el progreso de los pueblos y sus habitantes. 